\title{
O ENSINO DA LINGUA JAPONESA PARA ESTUDANTES BRASILEIROS DE NIVEL SUPERIOR
}

\section{L!dia Masumi Fukasawa}

Já tivemos a oportunidade de falar sobre a importância do conhecimento da Língua Japonesa para o estudo e a compreensão perfeita da sua Cultura. (1)

Humboldt já dizia (no século $X \mid X$ ) que "a língua não é um sim. ples meio de comunicação, mas a expressão do espírito e da concepção do mundo dos sujeitos falantes $(. .)$.$" . Segundo essa perspec-$ tiva, portanto, chegar-se ao conhecimento de qualquer aspecto da Cultura Japonesa significa a necessidade inevitável de passarmos pelo crivo de sua língua; significa a obrigatoriedade do estudioso de adquirir a habilidade suficiente para ler os textos em original, vale dizer, em Língua Japonesa, para evitar o distanciamento com o mundo cultural do japonês provocado pelos textos traduzidos.

Essa amplitude de conteúdos, que cabe à língua abarcar,colocanos diante de um aspecto de inequívoca importância e que tem sido objeto de nossas constantes preocupações nestes últimos anos: a tarefa ou a metodologia do ensino da Língua Japonesa para estudantes universitários brasileiros, cujas metas são as de estudar e de pesquisar a Língua Japonesa, sua Literatura, sua Cultura.

A aquisição da língua se faz, a grosso modo, mediante dois métodos distintos entre si, quais sejam: a aquisição por meio do método da automatização e por meio do método da descrição formal da língua.

Segundo nosso entender, o estudo da Língua Japonesa em nível superior deve pressupor um estudo científico sistematizado, racional e econômico, sendo essas qualidades inerentes e mais adequadas ao método gramatical, de descrição formal da língua. 
Quando dizemos "conhecer a Língua Japonesa", não nos referimos meramente à capacidade de realizar uma "conversação" nessa língua porque para o estudante de nível superior, a capacidade de descrevê-la formalmente deve ser anterior ao conhecimento da fala. O conhecimento da língua deve significar a capacidade de descrever cientificamente o seu funcionamento através de uma "linguagem gramatical".

0 acesso a essa linguagem deve ter como primeiro passo o estudo da Língua Japonesa através de sua gramática, em contraste com o Português. Através da referência a esses contrastes entre as duas línguas, podemos obter as diversas correspondências e divergências que nos proporcionarão os esquemas possiveis e não-possíveis de construção na passagem do Japonês para o Português e vice-versa. Só assim podemos detectar, com certa exatidão, as partes da estrutura que poderão vir a apresentar dificuldades, bem como a natureza dessas dificuldades.

Fornecer aos estudantes esse aspecto contrastivo e, como conseqüência, apontar as características da Língua Japonesa através da análise gramatical permite uma considerável "economia" na aprendizagem. Em outras palavras, para os universitários brasileiros, cuja língua materna é o Português, o aprendizado da Língua Japonesa através de explicaçőes gramaticais acelera o processo de apreensão das estruturas lingü isticas básicas. Tal afirmativa pode ser facilmente comprovada, bastando tomar como exemplo o aprendizado a que chega o estudante do 10 ano do Curso Básico de Língua Japonesa da USP, em aproximadamente 3 meses de aulas (6 horas semanais). Nesse curto período de tempo, o estudante se encontra capaz de escrever, de ler e de compreender perfeitamente o sentido de frases relativamente complexas, contendo vários sintagmas. No final do 19 semestre, ele está apto a entender, por exemplo, a seguinte frase:

Aniwa kinōkara genkini daigakuno senseito hikōkide tōi perūe kantanna chōsani dekaketa.

/O meu irmão mais velho, saiu, bem disposto, desde ontem, para o longínquo Peru, com o professor da faculdade, para um levantamento simples de dados./

Além do vocabulário contido na frase, foi necessário apenas apresentar-Ihe as partículas gramaticais indicativas dos casos (kakujoshi) em Japonês (WA $=$ sujeiro, $K A R A=$ procedência ou ponto de partida, $\mathrm{NI}=$ adjunto adverbial, $\mathrm{NO}=$ posse,, $\mathrm{TO}=$ companhia, etc.) e a 
flexão do verbo.

O estudo desses elementos gramaticais possibilita ao estudante combinar um número infinito de vocábulos, formando frases de sentido inúmero bastando para isso aumentar o repertório de seu vocabulário. Segundo essa sistemática, ao final de apenas 8 liçø̋es, o aluno adquiriu o conhecimento de, aproximadamente, 40 estruturas lingü ísticas, cerca de 500 ideogramas, encontrando-se apto a reconhecer frases com complementos de lugar, de direçao, de desejo, de procedência, de tempo, de finalidade, etc. 0 estudo sistematizado de alguns poucos elementos - kakujoshi (partículas indicativas dos casos), fukujoshi (partículas de ênfase ou limitação), jodōshi (particulas indicativas de modalidade), dőshi (verbos), Keiyōshi ("adjetivos") - Ihe permitirá compreender e produzir um sem número de frases.

Se $\circ$ método fosse o da conversação, vale dizer, o da aquisição das estruturas básicas da língua através da automatização (mesmo sendo em laboratório de l(ngua)., o aluno teria interiorizado, no máximo, a metade das estruturas adquiridas pelo "método gramatical".

Podemos dizer, portanto, que o método descritivo da língua o da classificação dos termos em categorias gramaticais - envolve um recurso mais econômico e prático do que o método da automatização utilizado nos cursos de conversação. Mais do que isso, o aprendizado da Língua Japonesa pela sua gramática possibilita o estudante a adquirir a capacidade de refletir sobre o funcionamento da língua, para uma metalinguagem, recurso esse que, aliás, constitui o objetivo maior do aprendizado de uma língua em nível universitário.

Foi através da caracterização da constituição da IIngua, isto é, da gramática que rege os principais instrumentos de construçao da frase (elementos nocionais, relacionais e nócio-relacionais da Língua Japonesa) que o estudante conseguiu chegar ao entendimento daquela frase citada anteriormente.

Segundo esse método, o aluno é levado a fazer um juízo de gramaticalidade sobre um conjunto infinito de frases (bastando aumentar o seu vocabulário), mesmo que nunca as tenha ouvido antes. A construção de frases agora não implica mais em memória nem em experiência vivida (como ocorre no método áudio-visual, onde o aluno terá de aprender cada uma das frases novas pela automatizaçăo). mas num sistema de regras gerais já interiorizado. Se ele aprendeu, por exemplo, que o kakujoshi GA, ligado a um taigen (nome, vocábulo nocional) introduz um sujeito ou um complemento de desejo, capacidade, etc., ele estará apto a reconhecer essas funçð̋es dentro de 
qualquer texto. Dar ao aluno as regras das componentes sintáticas de modo racional, gramatical, trará toda uma organização económica, altamente benéfica ao aprendizado das estruturas da língua.

Obedecendo a essa metodologia, ao longo de 22 lições, aproximadamente, dadas em um semestre e meio, o aluno terá aprendido as estruturas mais básicas da Língua Japonesa, o que o habilitará a ler e a compreender, embora ainda de maneira bastante rudimentar, um texto em Língua Japonesa. É evidente que esta parte praticamente "teórica" (porque o número de exercícios e de vocábulos será ainda pequenol terá de ser reaplicada nos textos, mas o contacto com os principais elementos gramaticais (joshi, jodōshi, taigen, yōgen, fuku. shi, etc.) permitirá ao aluno, com o aux́lio do dicionário, poder chegar à compreensão de um texto dado qualquer.

Caberá, a seguir, realizar o aprendizado de alguns elementos não contidos nas liçőes acima referidas, a saber: os usos peculiares que são mais facilmente explicáveis dentro do próprio texto - expressōes idiomáticas, setsuzokufukushi (conectivos), keishikimeishi (substantivos substitutivos), etc.

Não podemos rios esquecer também da gramática da IÍngua clássica, fator igualmente indispensável para a aquisição do conhecimento satisfatório da Língua Japonesa. A língua clássica explicará muitos dos elementos gramaticais ainda contidos na língua moderna e permitirá compreender melhor as leis que regulam as estruturas da língua. Além disso, voltando ao nosso ponto inicial, podemos dizer que ler as obras da literatura clássica através de textos traduzidos dificulta a apreensão do seu sentido, visto que o próprio filtro da tradução distancia o contacto com a real cultura da época.

Tanto o ensino da literatura (clássica ou moderna) quanto o ensino da própria Cultura Japonesa deve ter, necessariamente, um ponto em comum: o contacto direto com a Língua Japonesa.

Embora tenhamos salientado tão enfaticamente a importância do método grámatical contrastivo para o ensino da Língua Japonesa para estudantes brasileiros, somos impelidos a reconhecer as inúmeras dificuldades em aplicá-lo, pois, são pouquíssimos os estudos realizados nesse campo. São ainda inúmeros os assuntos a serem desvendados.

Levantaremos aqui alguns desses aspectos, referindo-nos primeiramente à natureza das dificuldades apresentadas comumente pelos nossos estudantes no aprendizado do Japonês, o que, segundo nosso entender, advém de dois aspectos fundamentais: (2) 
(A) das diferenças gramaticais referentes às estruturas lingüisticas das duas Iínguas;

(B) das diferenças culturais que podem ser registradas nas duas línguas.

São, naturalmente, inúmeros os elementos que se apresentam distintos quanto ao aspecto (A) mas gostaríamos de levantar alguns:

1. dificuldades na explicação de kakujoshi (partículas indicativas dos casos)

a) o agente da causativa: o agente da causativa é, na sua grande maioria, expresso pelo kakujoshi NI (dativo) e, em algguns casos, pelo kákujoshi O (acusativo). A diferenciação do uso em NI ou O parece não poder ser explicada simplesmente pela distinção jidōshi/tadöshi (verbos intransitivos/ verbos transitivos) (3), embora a tendência geral na construção da voz causativa seja o de transformar um verbo intransitivo em transitivo. A utilização de $\mathrm{NI}$ ou $\mathrm{O}$ deve recair sobre a natureza e o sentido dos verbos e, em última análise, sobre o problema de regência. Assim, em Japonês, torna-se possível construir uma voz causativa com verbos que denotam sentido de "resultado natural" ou "processo natural ("shizenno nariyuki" ou "onozukara shikaru")(4), isto é, com verbos cujo "processo é difícil de ser impedido". Exemplos:

- Hahaoyaga kodomoo nakaseru.

/A mãe faz a criança chorar./(5) (A mãe não pode impedir que a criança chore)

- Chōjoo hayaku shinasetekara okubyōni natta.

/Ficou medrosa depois que "deixou" a filha mais velha morrer/ (Não pôde impedir que a filha viesse a morrer.)

Segundo Yutaka Miyaji, 60 há cinco tipos de shieki (voz causativa):

(1) quando alguém move alguém e faz uma terceira pessoa praticar uma ação. Exemplo:

Chichiwa Hanakoni Tarōo shikaraseru.

/Meu pai faz Hanako repreender Tarô./

(2) quando alguém move alguém e faz esse alguém praticar uma ação. Exemplo: 
Chichiwa Hanakoni eigoo narawaseta.

/Meu pai fez Hanako aprender Inglês./

(3) quando há indicação de que alguém aprova a açáo de alguém. Exemplo:

Kyōwa kareo yasumaseyōka.

/Acho que vu deixá-lo faltar hoje./

(4) quando há indicação de que alguém reconhece a liberdade de ação de outra pessoa (quando não adiante interferir.) Exemplos:

Tarōo kujimade nekasete oita.

/Deixei Tarô dormir até às 9 horas./

Amari akanbōo nakaserunowa yokunai.

/Não é muito bom deixar a criança chorar./

Kareni katteni iwasete okusa.

Nou deixá-lo falar à vontade./

Damatte yamani ikasetewa abunai.

/É perigoso permitir que vá à montanha sem avisar./

(5) quando expressa sentido de amolação. Exemplo:

Ichijikanmo matasarete irairasaseraretawa.

/Fizeram-me esperar por uma hora e me fizeram ficar nervosa.

Embora o autor não aponte claramente, parece que os casos (1) e (2) recaem sobre o uso de NI para o agente da causativa e o (3), (4) e o (5) sobre o uso de O. Diriamos, então, que a voz causativa com $\mathrm{NI}$ carrega o sentido de "mando" para com o agente da causativa, de maneira mais forte, ao contrário do agente regido por 0,0 que atenua mais esse "mando". Assim, em Otōtoni benkyōsaseru. /Fazer o irmão mais novo estudar/, o valor causativo é mai mais forte do que em Otōtoo benkyōsaseru.

b) o complemento em O (kakujoshi) na "voz passiva indireta". Em Japonês, temos dois tipos de passiva:

A. foz passiva propriamente dita - quando o sujeito recebe, diretamente, a ação praticada pelo agente da passiva. Exemplo:

Senseini homerareta. /Fui elogiado pelo professor./

B. Voz passiva de interesse (rigaino ukemi) - quando a 
ação atinge o sujeito indiretamente. Esse tipo de passiva compreende 2 casos:

1) a passiva de amolação (meiwaku) formada com verbos intransitivos. Exemplo:

Kinodokuni. Ano onnamo kodomoni sakidatarete. . .

/Coitada. Aquela mulher. . . a filha the morreu. . . / (A filha morreu e ela está sofrendo com isso - conseqüência negativa)

2) a passiva indireta - é o objeto direto que sofre diretamente a ação do verbo e o sujeito sofre as conseqüências dessa ação. Exemplos:

Inuni ashio kamareta. /Tive o pé mordido pelo cão./ (O cão moredeu meu pé e eu, "por tabela", sofro com isso.)

Ishani ketsuekikensao susumerareta.

/Fui aconselhada pelo médico (a fazer) um exame de sangue./

O segundo tipo de passiva (passiva de interesse) é um dos pontos problemáticos no momento da sua transmissão aos estudantes brasileiros porque a nossa língua não prevê tais estruturas frasais. Em Japonês, os verbos chamados "inativos" (por Akira Mikami), tais como aru (existir), suru (fazer), iru (necessitar), muku (servir para, adequar-se a), niaù (cair bem), dekiru (ser capaz em), etc. nåo formam voz causativa ou passiva porque são verbos depoentes, já contendo em si o sentido de passividade ou de causalidade. Por outro lado, os verbos denominados "ativos" podem formar voz passiva, sendo que os intransitivos só formam passiva de interesse $(B)$ e os transitivos formam a voz passiva propriamente dita (A).

c) dificuldades apresentadas na discriminação do uso de WA (fukujoshi) e GA (kakujoshi) como sujeito da frase. Este é um assunto controvertido, mesmo entre os gramáticos mais recentes que estudam a Lingua Japonesa. Nos exemplos

Zōwa hanaga nagai. / Zoga hanaga nagai. 10 elefante tem uma tromba comprida/ 
Akira Mikami(8) considera Zōwa como sendo um sujeito comum da frase (tadano shugo) e Zōga como sujeito específico ou selecionado (toritateno shugo) em oposição ao elemento "outros animais".

Entretanto, Yasuo Okuda(9) distingue o uso de WA e GA da seguinte maneira: o joshi GA é utilizado para formar o sujeito de uma frase já citada anteriormente no contexto lingüistico (bunmyaku) ou já referido no contexto de situação (bamen). Assim, nos exemplos:

Bokuga tōbanda. /Eu sou o plantonista./ e

Bokuwa töbanda,

notamos que Bokuga surge na medida em que tenhamos já anteriormente citada, a idéia "alguém vai ser o plantonista". Nesse sentido, tōbanda constitui o elemento já conhecido dentro da conversa, sendo o elemento novo a ser comunicado, o sujeito Bokuga. Boku leu/ é especificado em oposição a Kimi /você/ ou Kare /ele/. No segundo exemplo, Bokuwa fornece a base ou o fundamento (konkyo) da mensagem a ser veiculada e o elemento tōbanda, a sua explicação (setsumei).

No caso de Zōwa hanaga nagai, Okuda consiera Zōwa como sendo o sujeito da frase e hanaga nagai como sendo uma expressão idiomática não-divisível, equivalendo a um predicado. Para ele, há, nesse exemplo, 2 casos nominativos no nivel formal ou morfológico (keitaijō) e 1 só sujeito no nível sintático (bunronjō). Só assim, segundo ele, poderíamos explicar as demais frases em que ocorreu o aparecimento de WA e GA. Vejamos outros exemplos:

- Bokuwa haraga tatsu. /Eu fico com raiva./

- Karewa Hanakosanni kiga aru. /Ele está interessado em Hanako.l

- Bokuwa hon'o yomu kotoga dekiru. /Eu posso ler o livro./

- Bokuwa kumiaito kankeiga aru. /Eu tenho ligaçóes com o sindicato./

- Bokuwa ginkoni kanega aru. /Eu tenho dinheiro no banco./

Tanto as explicações de Mikami quanto as de Okudà não 
nos deixam totalmente satisfeitos. Mikami pecou ao não prever para o caso de GA a análise desenvolvida por Okuda (sobre o "fator já mencionado anteriormente no contexto lingüístico ou no contexto pragmático"). Okuda, por sua vez, resolve de maneira simplista todos os sintagmas com GA, considerando-os, juntamente com o verbo, simples expressões idiomáticas, o que dificulta ao estudante estrangeiro a sua aprendizagem, pois, terá de memorizar cada uma dessas expressões. Ao considerar hanaga nagai, haraga tatsu, kanega aru, etc., como expressões indivisíveis, negaThes o valor de sintagmas ou a função sintática que encerram. Por exemplo, o GA da frase Hon'o yomu kotoga dekiru traz maior benefício se explicado como partícula que rege um complemento de capacidade.

De qualquer maneira, acreditamos na necessidade de serem amplamente revistos e refutados esses conceitos.

2. Além desses problemas referentes a kakujoshi levantados no item 1, podemos citar inúmeros outros que necessitam de estudos e sistematizaçôes, o que acarretará, se bem realizados, profundo avanço no método científico do ensino da Língua Japonesa. São eles: o problema do rentaisetsu (cuja extensão costuma ser por demais longa) enquanto correspondentes às nossas orações adjetivas; a natureza e a função do hojoyōgen (verbos auxiliares te-iru, te-aru, te-oku, te-miru, te-shimau, etc.l; a função dos chinjutsufukushi ladvérbios que invocam modalidade, tais como: yokumo ... surumonoda, ittai ... dearōka, etc.); os chamados keishikimeishi (substantivos substitutivos: ... mama, ... no yöda, ... suru monoda, etc.); a função dos shijigo (dêiticos); a sistematização das outras categorias de modalidade (chinjutsu/jodoshi); etc.

Dentre os pertencentes à categoria (B), isto é, referentes às dificuldades provenientes das diferenças culturais do Português e do Japonês, podemos citar o problema das expressões de respeito, modéstia e polidez (abundantes em Língua Japonesa, pois, podem fazer parte de quase todas as categorias gramaticais - ora surgindo nos sufixos ou prefixos, ora no próprio léxico: no substantivo (Ex.: otenki, gishasan); nos numerais (Ex.: gikutsu, gfutarisan); nos verbos (Ex.: mōshiageru, ossharu); nos "adjetivos" (Ex.: oyasashiikata); nos 
jodōshi (elementos relacionais configurados de modalidade); etc.

Não podemos nos esquecer também das dificuldades de se apreender 0 sentido de jihatsu (espontaneidade) advindas dos diferentes modos de apreensão dos fatos da natureza (Ex.: Furusatoga shinobareru, Samuku kanjirareru, Waruku omowareru, etc.) e do sentido e funções de certos verbos peculiares à Língua Japonesa (Ex.: verbos com sentido de "dar" e "receber": yaru, kureru, morau).

São, enfim, problemas de ordem variada - ligados às características da própria cultura japonesa e que se encontram refletidos na língua - que necessitam ser criteriosamente estudados.

Retomando a idéia desenvolvida no in ício do trabalho, devemos dizer ainda, que o sistema de ensino, a que almejamos;enfoca a língua enquanto descrição formal por acreditarmos ser ele fundamental e insubstituivel para uma pesquisa científica da Língua Japonesa.

$\mathrm{Na}$ trajetória do ensino do Japonés, não podemos nos esquecer que se trata do ensino de uma língua estrangeira para brasileiros e que o objetivo dele deve ser o de se chegar ao domínio dos instrumentos básicos e necessários para uma pesquisa científica.

\section{NOTAS:}

(1) Artigo publicado na Rev. Estudos Japoneses WI, São Paulo, Centro de Estudos Japoneses da USP, 1983.

(2) Este aspecto foi levantado também no artigo "Chünanbei shokokuni okeru nihongo kyöiku" a ser publicado por Geny Wakisaka e por mim na Rev. Nihongo Kyöiku nọ 53, Tóquio, Ed. Nihongo Kyōiku Gakkai, março de 1984.

(3) Cf. Kanae Sakuma - Gendai Nihongono Hyögento Gohō pp. 208-226 e Nihonteki Hyögenno Gengokagaku pp. 119-127.

(4) Kanae Sakuma - Nihonteki Hyōgenno Gengokagaku p. 120.

(5) As frases que servem de exemplos serão apresentadas com suas traduçóes literais (entre, / /) cujo intuito é 0 de possibilitar ao leitor detectar as diferenças estruturais das duas línguas enfocadas.

(6) Yutaka Miyaji - Joshi Jödoshi Shōsetsu pp. 90-93.

(7) Sakuma - Genday Nihongono Hyögento Gohō pp. 208-226.

(8) Akura Mikami - Zowa Hanaga Nagai.

(9) Yasuo Okuda - "Bunpó Kyōikuno Kaishin" pp. 217-229. 


\section{OBRAS REFERIDAS:}

- IWABUCHI, Tadasu - "Ukemi, kanō, jihatsu, shieki, sonkeino jodōshi" in Hinshibetsu Nihon Bunpō Köza - Jodōshi 11, nọ 8. Tóquio, Meijishoin, 1972.pp. 134-165.

- MATSUO, Osamu - "O - Kakujoshi" in: Joshi, Jodōshi Shōsetsu. Org. Akira Matsumura. Tóquio, Gakutōsha, 1969. pp. 335-340.

- MIKAMI, Akira - Zōwa Hanaga Nagai. Tóquio, Kuroshio Shuppan, 1973.

- MIYAJI, Yutaka - "Seru, Saseru - Shieki" in: Joshi, Jodōshi Shősetsu. Org. Akira Matsumura. Tóquio, Gakutōsha, 1969. pp. 89-96.

- MIYAJI, Yutaka - Shinpan Bunron - Gendaigono Bunpōto Hyōgenno Kenkyü. Tóquio, Meijishoin, 1979.

- OKUDA, Yasuo - "Hihanto Han "hihan" in: Zōwa Hanaga Nagai. Akira Mikami. Tóquio, Kuroshio Shuppan, 1973. pp. 217-228.

- SAKUMA, Kanae - "Shiekino Tekubari" in: Nihonteki Hyōgenno Gengokagaku. Tóquio, Kōseisha Kōseikaku, 1967.pp. 119-127.

- SAKUMA, Kanae - Gendai Nihongono Hyōgento Gohō. Toquio, Kōseisha Köseikaku, 1967. 